\title{
THE EXPLICIT INSTRUCTIONS ON CONNECTED SPEECH TO THE FIRST YEAR ENGLISH MAJOR STUDENT'S PERCEPTION AND PRODUCTION AT SCHOOL OF FOREIGN LANGUAGES - THAI NGUYEN UNIVERSITY
}

\author{
Bui Thi Ngoan ${ }^{1}$, Bui Thi Huong Giang ${ }^{2 *}$ \\ ${ }^{1}$ TNU - University of Sciences, ${ }^{2}$ Thai Nguyen University
}

\begin{tabular}{|c|c|c|}
\hline \multicolumn{2}{|c|}{ ARTICLE INFO } & ABSTRACT \\
\hline Received: & $15 / 3 / 2021$ & Connected speech is such an essential aspect of phonology that has an \\
\hline Revised: & $31 / 3 / 2021$ & $\begin{array}{l}\text { extreme influence on successful communication. Therefore, the study } \\
\text { was conducted to investigate the effectiveness of aspects of connected }\end{array}$ \\
\hline Published: & $31 / 3 / 2021$ & speech training on English language freshmen's perception and \\
\hline & & Thai Nguyen University. Forty first year freshmen in \\
\hline \multicolumn{2}{|l|}{ KEYWORDS } & English language classes were the study participants. They were \\
\hline \multicolumn{2}{|l|}{ Phonology } & the participants of experimental and control groups were at the same \\
\hline \multicolumn{2}{|l|}{ Connected speech } & level of connected speech awareness or not. Then, participants of \\
\hline \multicolumn{2}{|l|}{ Explicit instruction } & experimental group were instructed explicitly aspects of connected \\
\hline \multicolumn{2}{|l|}{ Perception } & $\begin{array}{l}\text { speech in } 7 \text { weeks while the participants of control group continued } \\
\text { their regularly classes. After treatment, both groups were asked to do }\end{array}$ \\
\hline \multicolumn{2}{|l|}{ Production } & $\begin{array}{l}\text { post-tests. The results in pre-tests and post-tests were compared to be } \\
\text { able to answer the research questions. The study results elicited both } \\
\text { groups had a higher result in recognition and production post-tests; } \\
\text { however, the experimental group outperformed control group. }\end{array}$ \\
\hline
\end{tabular}

\section{HƯỚNG DẪN TƯờNG MINH CÁC KHÍA CANH LIÊN NGŨ̃ ĐỐI VỚI KHẢ NĂNG NHẬN DIỂN VÀ SỬ DỤNG CỦA SINH VIÊN NĂM THỨ NHẤT CHUYÊN NGÀNH TIẾNG ẢNH TẠI TRƯ ỜNG NGOẠI NGŨ் - ĐẠI HỌC THÁI NGUYÊN}

Bùi Thị Ngoan ${ }^{1}$, Bùi Thị Hương Giang ${ }^{2^{*}}$

${ }^{I}$ Truòng Đại học Khoa học- ĐH Thái Nguyên, ${ }^{2}$ Đại học Thái Nguyên

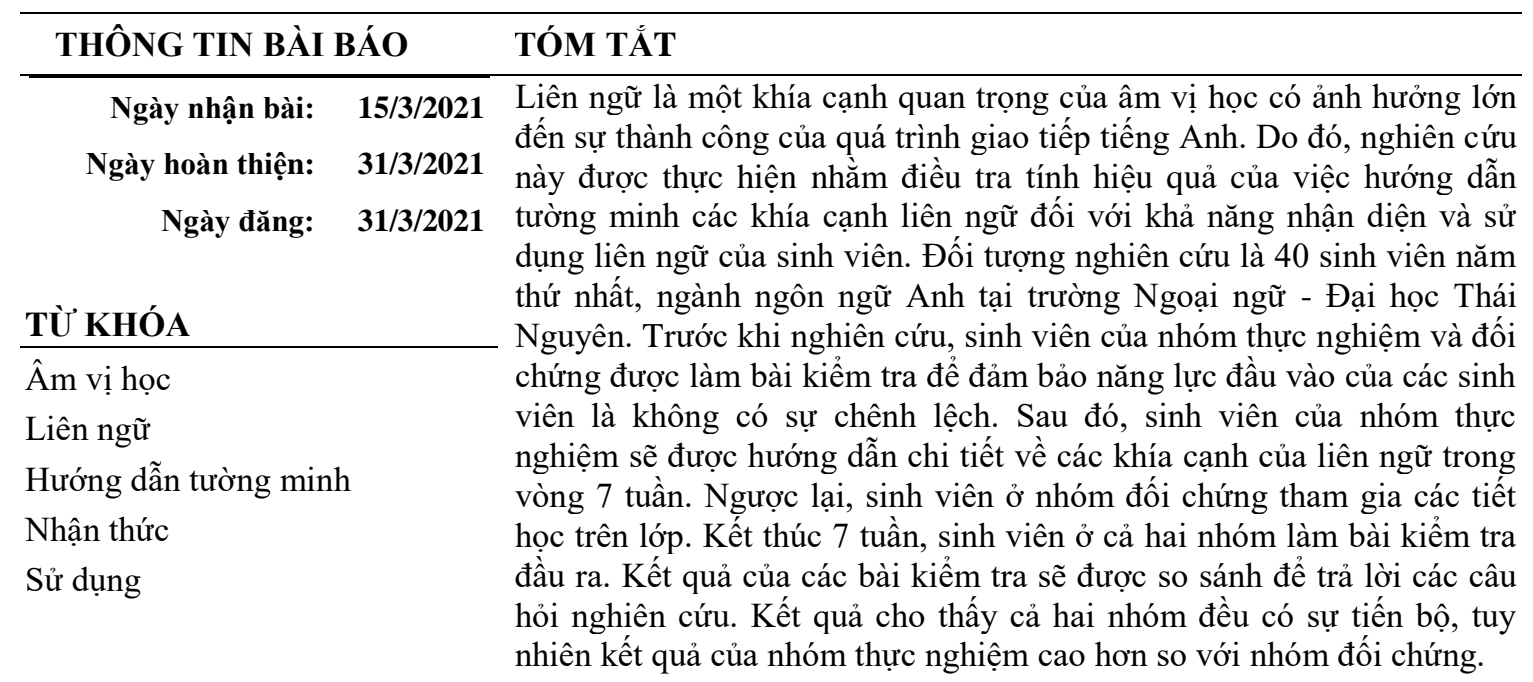

DOI: https://doi.org/10.34238/tnu-jst.4172

* Corresponding author. Email: bhgiang@tnu.edu.vn 


\section{Introduction}

Pronunciation is considered a very important foundation for listening and speaking skills. Its significance is also affirmed by numerous researchers. Robertson [1] reveals that learner's ability is severely limited without pronunciation skills; therefore, pronunciation is a must-have section in the training. Phuong et. al [2] quotes T. M. Derwing \& Munro [3] in saying that "pronunciation has been proved to be critical in ensuring the intelligibility of speech, thus, the success of communication". We cannot be denied that whether someone's messages can be passed or not depend on his/her pronunciation. In fact, almost all natives speak continuously and rapidly and they have a tendency to apply aspects of connected speech to keep their talk fluent and smooth. This is considered a trouble to English learners especially for those who follow isolating language like Vietnamese students. Therefore, listening to English native speakers' utterances seems to become more difficult. If someone cannot hear English well, he/she eventually is cut off from a conversation.

Gilbert [4] and Pennington et. al [5] point out that the suprasegmental features of spoken language play a critical part in the second language classroom. There were several authors researching this phenomenon (e.g: [6] - [8]) and proved that connected speech instruction can help learners to comprehend easily rapid speech. Furthermore, applying connected speech features can make learners sound more comprehensible and natural.

It can be seen that connected speech is such an important part of phonology in order to build a natural and flowing speech. Thus, for those who are learning English, especially English major students, they should pay more attention to this area. Thompson, T. et. al [9] says that the suprasegmental aspects of pronunciation can be improved by adult learners. Hammond [10] suggests that the best method is to provide explicit classroom pronunciation instruction. To examine whether teaching explicitly aspect of connected speech to Vietnamese adults is effective, I conducted the topic "the explicit instructions on connected speech to the first year English major students' perception and production at School of Foreign Languages - Thai Nguyen University." The study aimed at answering the following questions:

1. How does instructing explicitly assimilation and linking increase student's ability to recognize connected speech?

2. How does instructing explicitly assimilation and linking increase student's ability to produce connected speech?

\section{Methods}

\subsection{Participants}

Participants of the study were 40 students of two English language classes at School of Foreign Languages, Thai Nguyen University. There were 38 female students and 2 male students whose age ranged from 18 to 20 years old. The majority of them were 18 , whereas five of them were 19 and one student was 20.

Almost all participants have been learning English for seven to nine years. They are majoring in English language as a foreign language at University. They already learnt about basic pronunciation in the first semester. The experimental teaching was carried out in the second semester when student had fundamental foundation about phonology in order to achieve positive results. The participants were divided into two groups as a control group and an experimental group. Each group included 20 students.

\subsection{Data collection instruments}

Pre-tests and post-tests were designed to evaluate students' recognition and production ability.

The recognition test was used to examine how students understood the theory and realized linking and assimilation phenomena. This test consisted of two small parts which were listening 
test and listing test. Participants were given a fill-in-the-blank listening task which they had to fill missing words or statements. All missing information was real examples of assimilation and linking. Regarding listing test, students were asked to list the number of linking and assimilation phenomena in a given text. The score of these tests was based on the number of assimilation and linking recognized. That data would help the researcher evaluate the participants' recognition ability about two aspects of connected speech.

In terms of the production tests, the research oriented in students' reading text and speaking test. The production tests aimed at evaluating participants' ability to produce aspects of connected speech. Participants were required to read out a given text and make a conversation with their partners about familiar topics. All students' speeches were recorded and transcribed. All phenomena in their talk as well as produced phenomena were aggregated. The number of performed phenomena determined the score of participants.

\subsection{Procedure of data collection}

A quasi-experimental design was used for the present study. The research followed these following steps: Pre-test $\rightarrow$ Treatment $\rightarrow$ Post-test.

First of all, students of both groups were given pre-tests for checking their linking and assimilation perception and production ability. The pre-test was used to see whether all students of both groups were homogeneous in their knowledge of the items before starting research.

After taking pre-test, learners in experimental group were instructed explicitly aspects of connected speech. Whereas, students in control group still followed their regular instruction on the class.

Finally, students of control and experimental groups were given two post-tests in order to compare the range of improvement between them. The post-tests were the same format, level and language to the pre-tests to be able to evaluate accurately the differences between both groups in pre-tests and post-tests.

This study concentrated on aspects of connected speech; therefore, other areas such as grammar or vocabulary were skipped. The scoring of the test based on the number of assimilation and linking recognized and produced.

\subsection{Teaching procedure}

The students of experimental group were introduced explicitly about assimilation and linking during 7 weeks. Each lesson was designed in 2 periods. Each lesson was developed through these following six steps.

Step 1: Pre-listening (15 minutes)

Bottom-up listening approach was used to help students listen effectively when faced with unfamiliar vocabularies and structures. New vocabularies as well as new phrases were translated and explicated before listening. Teacher also provided students with background information of the recording to increase learners' comprehension. Guided questions or pictures were provided to focus students' attention on the main ideas of the recording. The goal of this stage was to make learners familiar with the topic they are going to listen.

Step 2: Listening comprehension checking (10 minutes)

Learners were presented with a recording. The recording was played twice. Next, students were asked to answer a few listening comprehension questions. The aim was to check their comprehension of the content they heard. This step also played an important role which made students realize what difficulties related to connected speech they encountered in listening are and understand the importance of connected speech (CS) for language acquisition.

Step 3: Fill in the blank and dictation (25 minutes)

A fill-in-blank listening task was designed and distributed to each student. Learners listened to short texts and sentences which contained different types of connected speech. Learners were 
asked to fill in the blanks of their answer sheets with the complete forms of the aspects of connected speech they heard.

Along with fill-in-the blank task, a dictation task was drown up which is a bit more difficult than fill-in-blank task. Before listening students were introduced new words related to the topic. The text was copied and distributed to students to compare with their notes before they were asked to produce the text. It is believed that through this active learner involvement, students come to confront their own strengths and weaknesses in English language use. In so doing, they find out what they don't know, then they find out what they need to know and this is the process by which they improve their language skills [11].

Step 4: Raising students' awareness of connected speech (20 minutes)

After getting used to aspects of connected speech through listening, learners were taught the connected speech by focusing on the sound changes and the rules which they follow. Teacher gave examples and asked students to guess the rules before providing theory. This approach helps students not only remember better but also realize aspects of connected speech in listening.

To guarantee that students can produce aspects of connected speech right after instruction, imitation was used to improve students' production ability. In this stage, learners were asked to listen to the recording to see how the sound changes, then imitate and repeat target words.

Step 5: Connected speech perception exercises (15 minutes)

Learners were asked to write a few examples of connected speech which they were taught in the lesson. Then, students were also given a text to list phenomena that they were introduced in the session. The aim of this step was to help learners to learn and internalize aspects of connected speech. So they could understand and use aspects of connected speech of the language they heard.

Step 6: Connected speech production exercises (15 minutes)

Practice is an essential step that helps students apply the theory into real communication. The goal of this step was for the students to be able to apply the rules into their own free speech. Gilner [12] appreciated the importance of communication tasks and considered as the final step which skills and knowledge become internalized as the learned patterns are integrated into spontaneous production (p.95). In this study, students were asked to read word lists and discuss on a given topic using the previously taught "reduced forms" of English. Students can work in pair followed teachers' requirements. The students' production was carefully controlled by the teacher; subsequently, the students were given feedback on their pronunciation.

\section{Results and discussion}

\subsection{Mean comparison of two groups on pre-test}

\subsubsection{The data from recognition pre- test}

To examine the connected speech recognition ability of students in the pre-test, a recognition test was designed with two parts including listening test and listing test. The result was handled by "Independent-Samples T Test".

Table 1. Mean comparison in connected speech recognition of both groups on pre-test

\begin{tabular}{llll}
\hline Groups & N & Mean & Sig. \\
\cline { 1 - 2 } Experimental group & 20 & 3.0250 & 0.639 \\
\cline { 1 - 2 } Control group & 20 & 3.1550 & \\
\hline
\end{tabular}

Participants' scores were calculated and Independent-Samples T- test was run to find the mean of each group. As seen on Table 1, the difference between control group and experimental group was negligible. The mean of control group was 3.1550 which was a bit higher than experimental group with a mean of 3.0250. The probability value of recognition test was $0.639(\mathrm{p}>.05)$. It means that recognition ability of both groups had similarities in listing test and listening test. 


\subsubsection{The data from production pre- test}

Regarding production pre-test, a "reading text" test and speaking test were used to assess participants' performance. Table 2 and 3 indicated that producing aspects of connected speech through reading a given text and speaking was not too different.

The result from table 2 indicated that the performance of control group and experimental group were approximately similar in "reading text" pre-test with the probability value was .980 exceeding $\mathrm{p}=0.05$.

Table 2. Mean comparison of two groups' performance on the reading text pre-test

\begin{tabular}{llll}
\hline Group & N & Mean & Sig. \\
\cline { 1 - 3 } Experimental group & 20 & 1.5080 & \multirow{2}{*}{0.980} \\
\hline Control group & 20 & 1.5140 & \\
\hline
\end{tabular}

Almost all learners of both groups got troubles in producing aspects of connected speech in their conversations. There was not any considerable difference between experimental group and control group (table $3, \mathrm{p}=.501>.05$ ).

Table 3. Mean comparison of two groups' performance on the speaking pre-test

\begin{tabular}{llll}
\hline Group & $\mathbf{N}$ & Mean & Sig. \\
\cline { 1 - 2 } Experimental group & 20 & 2.2400 & 0.501 \\
\cline { 1 - 2 } Control group & 20 & 1.8055 & \\
\hline
\end{tabular}

\subsection{Mean comparison of both groups on pre-tests and post-tests}

In order to examine the variance between two groups' performance on the pre-tests and posttests, paired-samples t-tests were employed. The statistics were shown below.

\subsubsection{The participants' "connected speech recognition"}

After training course, there were obvious differences between two groups on pre-test and posttest. According to statistics, it exposed that the mean of experimental group and control group on connected speech recognition in post-test was higher than their pre-test means $(p=0.000<.05)$. However, the mean of experimental group is much more considerable than that of control group $($ experimental group $=2.25750$, control group $=.98550)($ table 4 and table 5$)$.

Table 4. Mean comparison of the experimental group's recognition pre and post- test

\begin{tabular}{cc}
\hline Mean & Sig. \\
\hline 2.25750 & 0.000 \\
\hline
\end{tabular}

Table 5. Mean comparison of the control group's recognition pre and post- test

\begin{tabular}{cc}
\hline Mean & Sig. \\
\hline 0.98550 & 0.000 \\
\hline
\end{tabular}

\subsubsection{The participants' "connected speech production"}

The picture of connected speech production comparison was not different from recognition. According to the comparison mean from Paired-samples t- tests, both groups had higher results in their post-test. The mean of control group, however, just rose steadily by 0.41150 following experimental group with a mean of 1.08700 (table 6). With $p=0.000$, both groups had significant differences.

Table 6. Mean comparison of both groups on reading test

\begin{tabular}{lcc}
\hline & Mean & Sig. \\
\hline Experimental group & 1.08700 & 0.001 \\
\hline Control group & 0.41150 & 0.000 \\
\hline
\end{tabular}


Table 7 compared the participants' ability of applying aspects of connected speech into their conversation. In comparison with pre-test, both groups changed positively. The probability value of control group was .000 and experimental group was .001.

Table 7. Mean comparison of the both groups on speaking test

\begin{tabular}{lcc}
\hline & Mean & Sig. \\
\hline Experimental group & 1.75500 & 0.001 \\
\hline Control group & 1.24000 & 0.000 \\
\hline
\end{tabular}

\subsection{Mean comparison of both groups on post-test}

\subsubsection{Assimilation and linking recognition}

As results obtained, the post-test mean of the experimental group on recognition test was higher than mean of the control group. However, to check if it was significant or not, several Independent-samples t- tests were used to compare control group's mean with experimental group's mean in their recognition post-test. Table 8 exposed that there was a noticeable difference between the result of control group and experimental group in recognition post-test ( $\mathrm{p}$ $=.002<.05)$.

Table 8. Mean comparison of two groups on recognition post-test

\begin{tabular}{llll}
\hline Groups & N & Mean & Sig. \\
\cline { 1 - 2 } Experimental group & 20 & 5.2825 & 0.002 \\
\cline { 1 - 2 } Control group & 20 & 4.1405 & \\
\hline
\end{tabular}

\subsubsection{Assimilation and linking production}

The result from table 9 illustrated that the mean of experimental group outperformed the control group $(\mathrm{p}=0.042<0.05)$.

Table 9. Mean comparison of two groups on reading post-test

\begin{tabular}{llll}
\hline Groups & N & Mean & Sig. \\
\hline Experimental group & 20 & 2.6190 & 0.042 \\
\cline { 1 - 2 } Control group & 20 & 1.9305 & \\
\hline
\end{tabular}

Another Independent-samples t-test pointed that there was a significant difference between two groups' performance on the connected speech production test (speaking) with $p=0.009<$ 0.05. Although both groups witnessed a more positive result in post-test, the experimental group had a higher result in comparison with control group. Hence, it could be concluded that aspects of connected speech instruction was helpful in raising the learners' application ability in their daily conversation.

\subsection{Discussion}

It is believed that listening is closely-related to speaking skills. Rankin [13] indicated that listening is the most frequently used language activity and has a close relationship with speaking skills. According to the study of Abu-Snoubar [14] listening has an influence on the development of oral proficiency in EFL classes. To help EFL learners improve their listening and speaking skills, researchers investigated the impacts of different factors. Among many proposals, researchers seem to have the same opinion that connected speech is one of the main reasons for unsuccessful interactions. Authors pointed that production of connected speech not only helps learners' speech to be more fluent [15] but also has positive effects on their receptive skills [16]. Inspired by the existing literature, this study tried to test the effect of English "reduced forms" instruction on students' perception and production. 
After comparing means from pre-tests and post-tests, the research questions were able to be answered obviously. There was a difference between the control group and the experimental group after instructing aspects of connected speech explicitly. Giving explicit instruction brought positive results in terms of participants' perception and production ability. However, the findings also indicated that students could recognize better than produce aspects of connected speech. The average score in listening test was improved in post-test. The experimental group increased considerably while the control group saw a slight rise. It can be determined that teaching aspects of connected speech helped students realize assimilation and linking better in listening. In comparison with listening test, learners had difficulties in recognizing aspects of connected speech in a text. Although there were improvements, they were trivial. Students' production capability also went up after investigation. However, the pre/post-test results indicated experimental group's performance was better than the performance of the control group. Although control group could produce aspects of connected speech better than the experimental group in the pre-tests, the experimental group outperformed in the post-tests. Therefore, teaching connected speech had a positive effect on students' production.

The results are also in line with Mhammad Saber Khaghaninezhad \& Ghasem Jafarzadeh [17] who determined that teaching "reduced forms" helped students to master their listening and speaking skills. There was a significant difference between two groups after treatment. His study investigated male learners at different age range in 10 weeks opposed to the present study which lasted for 7 weeks for younger female participants. Although there were differences about participants' age, gender and research duration between two studies, the results approved that explicit instructions on connected speech did wonder for learners' perception and production.

Baghrahi [18] approved that raising assimilation knowledge could improve learners' listening comprehension. Author used two tests to evaluate effects of teaching assimilation on listening comprehension including Cambridge Preliminary English Test (PET) and connected speech forms Dictation Test, while the present research only used fill-in-blank test to check the ability of recognizing aspects of connected speech in listening. Although the aim of two studies were different; however, the recognition of connected speech is the foundation for listening comprehensively. Therefore, the result from Baghrahi's research could compare correlatively with the present study. Both studies witnessed an improvement in listening which was an evidence for the benefit of teaching assimilation.

Alameen [19] investigated three groups AV (Audio visual) group, AO (Audio only) group and a control group to evaluate the impacts on learners' perception and production. Groups could raise awareness about linking, but they did not make significant improvement in production. The results from Alameen's study were similar to the current research although the participants of two studies were a bit different. While the present study focused on the first year English major student in a university in Viet Nam, the participants of previous study were studying in the US. Learning and teaching environment among participants was totally different, but the studies' results approved that instructing aspects of connected speech was advantageous to students' recognition ability.

Whether there were certain differences and similarities about participants, gender or even learning environment, the results from previous studies had similarities with the current study. They exposed that teaching aspects of connected speech brought undeniable benefits to English learners. Hopefully, instructing aspects of connected speech would be widely taught for English learners.

\section{Conclusion}

This experimental study represents the researchers 'efforts to investigate a very real part of language to improve students' listening and speaking skills. Although research still has certain limitations, however, it also provides a valuable opportunity for researchers to have thorough 
insights into the importance of phonology, especially aspects of connected speech in teaching and learning a foreign language. It is hoped that students would benefit from this study and would devote more time and effort to improve knowledge of phonology which brings great contribution to language acquisition.

\section{Acknowledgement}

Working on this research has been an extremely invaluable and rewarding experience. This was made possible by the support, encouragement and guidance from many people. This paper would not have been completed without the support from all of whom I am profoundly indebted.

I would like to thank lecturers at School of Foreign languages and students of N06 and N08 classes who helped me a lot during my research. I am truly grateful to my colleagues for their wholehearted care and support during the time I conducted the study. My study could not have been completed with such great satisfaction without their encouragement and consolations.

\section{REFERENCES}

[1] Robertson, "Teaching English pronunciation skill to the Asian learner," Asian EFL Journal, vol. 5, no. 3 , pp. 1-26, 2003.

[2] T. Phuong, "Vietnamese Learners' Perspectives of Corrective Feedbacks on English Pronunciation," The Asian ESP Journal, vol. 15, no. 2, pp. 70-82, 2019.

[3] T. Derwing, "Second language accent and pronunciation teaching: A research-based approach," TESOL quarterly, vol. 39, no. 3, pp. 379-397, 2005.

[4] J. Gilbert, Clear speech. Cambridge University Press, 2001.

[5] M. Pennington, "Pronunciation revisited," TESOL Quarterly, vol. 20, no. 2, pp. 207-225, 1986.

[6] J. Brown, "The effectiveness of teaching reduced forms of listening comprehension," RELC Journal, vol. 17, no. 2, pp. 59-70, 1986.

[7] Celce-Murcia, Teaching Pronunciation: A Reference for Teachers of English to Speakers of Other Languages. Cambridge University Press, 1996.

[8] Matsuzawa, "Comprehension of English reduced forms by Japanese business people and the effectiveness of instruction," in Perspectives on teaching connected speech to second language speakers. Honolulu: University of Hawai'i, National Foreign Language Resource Center, 2006, pp. 59-66.

[9] T. Thompson, "The importance ofteaching pronunciation to adult learners," Asian EFL Journal, vol. 2, no. 1, pp. 1-11, 2005.

[10] R. M. Hammond, "Foreign accent and phonetic interference: The application of linguistic research to the teaching of second language pronunciation," in Second language acquisition theory and pedagogy. Routledge, 1995, pp. 293-303.

[11] R. Wajnryb, Grammar Workout: The Dictogloss Approach, Listening-Text Reconstruction-Analysis. Melting Pot Press, 1986.

[12] L. Gilner, "Pronunciation Instruction: A Review of Methods and Techniques," Journal of School of Foreign Languages, vol. 35, pp. 93-108, 2008.

[13] P. T. Rankin, "The importance of Listening Ability," English Journal, vol. 17, pp. 623-630, 1929.

[14] T. K. Abu-Snoubar, "On the Relationship between Listening and Speaking Grades of Al-Balqa Applied University English as a Foreign Language Students," International Education Studies, vol. 10, no. 12, pp. 130-139, 2017.

[15] J. Morely, "The pronunciation component of teaching English to speakers of other languages," TESOL Quarterly, vol. 25, pp. 481-529, 1991.

[16] C. Hill, "Contraction and blending: The use of orthographic clause in teaching pronunciation," TESOL Quarterly, vol. 14, pp. 299-323, 1980.

[17] M. Khanhaninezhad, "Investigating the Effect of Reduced Forms Instruction on EFL Learners' Listening and Speaking Abilities," English Language Teaching, vol. 7, no. 1, pp. 159-171, 2014.

[18] A. K. Baghrahi, "The effects of assimilation and elision teaching on listening comprehension of EFL junior high school students," International Journal of Language Learning and Applied Linguistics World, vol. 5, pp. 264-273, 2014.

[19] G. Alameen, "The effectiveness of linking instruction on NNS speech perception and production," Doctoral Dissertation, Iowa State University, 2014. 